\title{
Letrônica
}

\section{Paradoxo de Sorites: uma reflexão semântica sobre vagueza}

\section{Sorites Paradox: a semantic reflection about vagueness}

Doutora em Letras - Linguística pela Pontifícia
Universidade Católica do Rio Grande do Sul (PUCRS) com bolsa da Coordenação de Aperfeiçoamento de Pessoal de Nivel Superior (CAPES).

E-mit/orid.org00000001-6213-3894 E-mail: nanashara.behle@gmail.com

Recebido em: 10/11/2018 Aprovado em: 8/3/2019.

Publicado em 23/9/2019.

Endereço para correspondência: Programa de Pós-Graduação em Letras Av. Ipiranga, 6681 - Partenon 90619-900, Porto Alegre, RS, Brasil
Nanashara Behle ${ }^{1}$

Pontificia Universidade Católica do Rio Grande do Sul, Porto Alegre, RS, Brasil.

\section{RESUMO}

No cotidiano, usamos palavras e expressões vagas sem muitas vezes pensarmos sobre isso ou causarmos estranheza em nossos interlocutores. São predicados de vagueza, nos quais a propriedade de ser vago pode não ser tão explícita. Esses predicados são casos incertos ou com a fronteira semântica limítrofe, o que dificulta a clareza da extensão do predicado em si. 0 objetivo principal deste trabalho, é avaliar os encadeamentos soríticos em uma interface entre a linguística e a lógica. Visto que a vagueza é observada nessas duas áreas do conhecimento. Na lógica, esse tipo de predicado possibilita o desenvolvimento do chamado paradoxo de Sorites, cujo argumento pode ser construído por encadeamento das premissas ou por indução matemática. Usamos, nesse trabalho, o estudo filosófico da vagueza e do paradoxo (PETRILLO, 2005) e, também, o estudo linguístico, em uma semântica de condições de verdade (CHIERCHIA; MCCONNELL-GINET, 1990), para refletirmos sobre como a vagueza é tratada na linguagem. Palavras-chave: Sorites. Vagueza. Semântica.

\section{ABSTRACT}

We use vague words and expressions without perceiving or causing strangeness in our interlocutors in everyday language. They are vague predicates, in which the property of being vague may not be so explicit. These predicates are uncertain cases or cases with the semantic boundary make difficult to clarify the extension of the predicate itself. Vagueness is assessed in both logic and linguistics studies. In logic, this type of predicate enables the development of the so-called Sorites paradox, whose argument can be constructed by chaining the premises or by mathematical induction. We use in this paper a philosophical study of vagueness and Sorites paradox (PETRILLO, 2005) and also a linguistic study, in semantics based on truth conditions (CHIERCHIA; MCCONNELL-GINET, 1990), to reflect about the way vagueness is treated in language.

Keywords: Sorites. Vagueness. Semantics. 


\section{Considerações iniciais/introdução}

$\mathrm{N}$

a linguagem natural, utilizamo-nos cotidianamente de expressões de enunciados que não parecem ser problemáticos quanto ao seu significado, mas que, se observamos atentamente, perceberemos que a interpretação contida neles não é tão clara. No entanto, como utilizamos frequentemente sentenças com predicados desse tipo, parece importante e interessante pensarmos um pouco sobre eles. Alguns desses casos, que desafiam os estudos da lógica e da linguagem, estão demonstrados em um paradoxo relacionado à vagueza, o Paradoxo de Sorites.

Neste artigo, portanto, temos como intuito principal refletir sobre como a vagueza pode ser observada sob um viés linguístico, mais precisamente em uma perspectiva formal da semântica, a qual atua em interface com estudos lógicos. Nos estudos da linguagem, a vagueza é analisada principalmente em pesquisas com abordagem semântica (BACH, 1989; CHIERCHIA; MCCONNELL-GINET, 1990). É possível pensarmos nessa propriedade também em um viés pragmático nos termos das inferências linguísticas (GRICE, 1975; SPERBER; WILSON, 1986/1995), ou seja, a vagueza é uma propriedade relevante para as duas áreas. No entanto, neste trabalho, não abordaremos questões do nível pragmático, perspectiva apresentada em Behle (2019).

Pensar sobre o modo que fenômenos como os paradoxos ocorrem na linguagem natural sem, em um primeiro momento, causar ruídos no entendimento do significado, é um interesse recorrente nos nossos estudos (ver BEHLE, 2014; 2019). Este trabalho é uma consequência natural de nossa pesquisa, servindo como mais um bloco na discussão teórica sobre paradoxos com o olhar linguístico.

Para construirmos nossa reflexão, começaremos apresentando o que é o Paradoxo de Sorites, representante importante dentre os paradoxos que se valem da ideia da vagueza e da imprecisão, e como ele é desenvolvido e tratado em termos dos estudos lógicos. Em seguida, nos deteremos na perspectiva da semântica formal para o conceito de vagueza de modo a mostrarmos as bases teóricas dos estudos linguísticos pertinentes ao nosso trabalho. Finalizaremos com uma ilustração dessas noções da linguagem e da lógica para a formulação de um argumento sorítico.

\section{0 paradoxo de Sorites}

Nesta primeira parte, como mencionamos, mostraremos o que é o paradoxo de Sorites e apresentaremos alguns modos utilizados para abordá-lo, considerando aspectos formais.

Dadas as premissas (1), (2) e (3) abaixo:

(1) João é uma criança de 2 anos.

(2) O filho de Maria é uma criança de 13 anos.

(3) Paula é uma criança de 16 anos.

(1) e (2) certamente não causam estranheza no uso do predicado criança, mas, enquanto em (1) não teríamos dúvidas quanto a, em caso de necessidade, levar João a um pediatra, talvez não estaríamos tão certos quanto à especialidade do médico do filho de Maria em (2) seria a mais adequada. Qual idade estabelece que uma pessoa deixa de poder ser mencionada com o predicado "criança"? Em (3), utilizar "criança” parece ser inadequado, embora não seja consenso o seu uso. Mas a sua aceitabilidade, em comparação aos exemplos (1) e (2), nos serve para começarmos a pensar sobre o raciocínio paradoxal que enfrentamos em paradoxos de vagueza. Isso porque não há um limite claro estabelecido para o predicado, pelo menos não racionalmente. 
A propriedade da vagueza é aplicada para uma gama de paradoxos que circundam uma noção de indefinição e incerteza. A vagueza, nos fenômenos dessa natureza, acontece porque, quando um termo T é vago, obrigatoriamente um termo não $\mathrm{T}(\neg \mathrm{T})$ também o será. De acordo com Rescher (2001), cria-se uma zona difusa entre as situações propiciadas por $\mathrm{T}$ e por $\neg \mathrm{T}$, na qual tendemos a interpretar o termo nos dois modos. Essa noção fica mais clara ao visualizarmos os paradoxos da vagueza, os quais serão ilustrados aqui com formulações do Paradoxo de Sorites.

Esse tipo de raciocínio em paradoxos remonta ao filósofo Eubulides de Mileto, da escola Megárica. O nome do paradoxo de Sorites deriva da palavra grega soros, que significa monte, em uma referência a sua tradicional formulação sobre montes ou punhados de areia (que veremos mais adiante) e, por isso, também é conhecido como paradoxo do "Monte de Areia". Vamos imaginar um monte de areia com 20.000 grãos de areia (T). Caso removêssemos 1 grão, certamente não deixaria de ser um monte de areia, ou um não monte $(\neg T)$. Então 20.000 grãos de areia e 20.000 - 1 grão de areia equivalem a um monte de areia. Se alguém retirasse um grão por vez do monte $(n-1)$, ainda assim não saberíamos precisar quando ele deixaria de ser um monte de areia. Ólin (2003) e outros estudiosos desse paradoxo afirmam que, seguindo o raciocínio de que o monte continua sendo um monte a cada grão tirado, chegaríamos à conclusão de que um grão de areia seria suficiente para considerarmos um monte de areia. É esse encadeamento argumentativo que faz o fenômeno do paradoxo emergir, pois racionalmente a conclusão é absurda por contrariar o princípio lógico da não contradição. Na linguagem, observamos que também é uma ideia sem sentido, mas amplamente aceita no cotidiano. Esse paradoxo fica evidenciado na pergunta: Em que momento um monte de areia deixa de ser um monte conforme removemos os grãos? Vários autores apresentaram esse paradoxo, mas com pequenas variações em sua formulação. Apresentamos, aqui, algumas dessas versões.
Hyde e Rafman (2018) apresentam o paradoxo de duas maneiras: com a forma condicional e com indução matemática, como segue. 0 paradoxo evidenciado através da série de condicionais usa modus ponens, sendo ' $\mathrm{X}$ ' um predicado sorítico e $\alpha \mathbf{n}$ (no qual $\mathbf{n}$ é um número natural) um valor para a série de predicados de 'X'. Vejamos em (4).

(4) $\mathrm{X} \alpha_{1}$

$$
\begin{aligned}
& \text { Se X } \alpha_{1} \text {, então X } \alpha_{2} \\
& \text { Se X } \alpha_{2} \text {, então X } \alpha_{3} \\
& \text { Etc. } \\
& \text { Se X } \alpha_{(\mathrm{n}-1)} \text {, então X } \alpha \text { n } \\
& \hline \mathrm{X} \alpha \mathrm{n}
\end{aligned}
$$

Quanto à série de condicionais de Sorites, Ólin afirma:

Nessa forma, o argumento consiste em uma sequência de sub-argumentos, cada um da forma do modus ponens, e cada um contendo uma diferente categoria e uma premissa condicional. 0 primeiro passo do argumento é direto e raramente contestado. A sequência de condicionais, que é mais propensa a receber críticas, reflete a visão de que o predicado em questão é insensível a pequenas diferenças ${ }^{1}$ (ÓLIN, 2003, p.168-169, tradução nossa).

A outra maneira proposta por Hyde e Rafman (2018) é realizada por indução matemática, um esquema mais compacto do que a série anterior, pois utiliza uma generalização universal, no caso, sobre ser ou não um monte:

${ }^{1}$ Do original: In this form, the argument consists in a sequence of sub-arguments, each of the form modus ponens, and each containing a different categorical and conditional premise. The first step of to draw critical fire, reflects the view that the predicate in question is insensitive to small differences. 
(5) 20.000 grãos de areia formam um monte.

(6) Um grão de areia não forma um monte.

(7) Caso n não seja um monte, $(n+1)$ grãos de areia também não é um monte.

(8) Caso n seja um monte, $(n-1)$ grãos de areia também é um monte.

Enquanto (5) e (6) não provocam nenhum espanto, (7) e (8) nos fazem refletir. Isso porque as premissas (5) e (6) são as etapas básicas para os passos indutivos em (7) e (8). Além disso, apesar de (7) e (8) parecerem premissas verdadeiras, nos levam a conclusões absurdas que também evidenciam o paradoxo do monte de areia.

Eubulides de Mileto desenvolveu outra formulação do Paradoxo de Sorites que se refere ao fato de uma pessoa ser ou não ser careca. Assim como no caso do monte de areia, é difícil elaborarmos quantos fios de cabelo são necessários uma pessoa perder para ser considerada careca. Obviamente uma pessoa com a cabeça completamente preenchida por fios de cabelos não é careca, mas alguém com nenhum fio de cabelo é inegavelmente careca. Já uma pessoa que possua pouco cabelo nas têmporas (as popularmente chamadas "entradas") ou outra com ainda menos cabelo em cima da cabeça poderiam receber o predicado "careca"?

Então podemos demonstrar pelo método indutivo, em (9), (10), (11) e (12), que:

(9) Se perde um ou dois fios, não é careca.

(10) Se perde cem mil fios é careca.

(11) Se perde $\mathrm{n}$ fios não é careca, também não o seria $(n-1)$ fios.

(12) Se perde $n$ fios é careca, também o seria $(n+1)$ fios.

Segundo Petrillo (2005, p. 24), há quatro tipos de respostas, mais recorrentes na literatura, para avaliar o Paradoxo de Sorites, as quais veremos a seguir. i. Negar a validade dos argumentos, de modo a não aceitar a prerrogativa de que a conclusão advém das premissas.

ii. Contestar a verdade de uma das premissas genéricas ou de algum condicional.

iii. Rejeitar a hipótese de verdade de uma das premissas ou a falsidade da conclusão, apesar de aceitar a validade do argumento da indução.

iv. Utilizar o quantificador universal $(\forall)$ e o existencial $(\exists)$ para expressar sentenças qualitativamente vagas, de modo a dissolver o paradoxo em sentenças com o uso de termos como muitos, alguns e vários.

Sobre o caso (i), Dummett (1978) e Petrillo (2005) consideram que seria necessário abandonar a regra de inferência por modus ponens, o que ocasionaria um impasse para a construção do fenômeno. Isso porque o Paradoxo de Sorites precisa dessa norma para a construção do argumento do paradoxo, pois ficaria inviável sabermos qual seria a proposição seguinte para o próximo passo sorítico. O principal problema, nesse caso, seria a necessidade de quebrar uma regra lógica como modus ponens, o que, segundo os autores, não é coerente devido sua força. 0 mesmo ocorre com a negação do encadeamento dos condicionais do paradoxo.

O caso (ii) parece trazer outra problemática para a manutenção do paradoxo de Sorites, já que há a necessidade de aceitarmos que n seja verdadeira, mas que $(n+1)$, por exemplo, seja falso, segundo Petrillo (2005). Desse modo, não estaríamos lidando com predicados vagos (os quais abordaremos de maneira mais precisa, em uma abordagem semântica, na próxima seção deste artigo).

Nesse caso, também entram aqueles que admitem uma perspectiva de gradação dos predicados, a qual defendem que é preciso considerar o que está próximo da verdade, conjecturando que as premissas não são totalmente 
verdadeiras. Assim, não é possível assumir uma lógica tradicional bivalente, apenas uma mais difusa que permite diferentes graus entre a falsidade total (0) e a verdade total grau (1) ${ }^{2}$.

No caso (iii), as inferências realizadas no paradoxo são questionadas uma a uma e assim acredita-se que a lógica tradicional não pode ser usada para avaliar noções vagas na linguagem natural. Portanto, se assumirmos a forma desse caso, reconhecemos que o paradoxo de Sorites não pode ser avaliado logicamente.

O caso (iv) é o destacado por Petrillo (2005) em seu trabalho e parece (juntamente com o caso ii) bastante adequado em uma perspectiva semântica. Quantificadores universais e existenciais permitem expressar noções imprecisas e indeterminas sobre quantidades, modalizando, deste modo, os limites das quantidades sem abandonar a lógica.

Agora que apresentamos o paradoxo de Sorites, mostrando como ele é construído, com alguns exemplos e diferentes abordagens de tratamento, vamos nos aprofundar no conceito de vagueza e de quantificação modular sob uma perspectiva formal da semântica linguística.

\section{A noção de vagueza e quantificação modular nos estudos Semânticos}

Nesta segunda seção, trataremos da noção de vagueza e de quantificação universal e existencial na semântica. Como dissemos anteriormente, a semântica que abordamos neste artigo se baseia em aspectos formais. Portanto, algumas questões usadas para entendermos o paradoxo de Sorites, na seção anterior, subjazem ao mesmo escopo de estudo. No

${ }^{2}$ Como nosso intuito neste texto é apresentar brevemente questões sobre o paradoxo de Sorites, não problematizaremos a questão da divisão dos graus. entanto, pretendemos mostrar aqui como esses conceitos são vistos por estudiosos da linguística propriamente dita em contraponto com a seção anterior.

Para pensarmos sobre vagueza na linguagem, antes precisamos diferenciá-la da noção de ambiguidade, uma vez que são passíveis de confusão. A ambiguidade se origina de polissemia ou homonímia, de modo que ela pode ser considerada um fenômeno direto, pois o contexto é o que nos mostra qual o sentido a ser utilizado em determinada sentença (CANÇADO, 2012). Já na vagueza, o contexto atua de modo indireto, pois ele pode acrescentar informações extras ao sentido e, além disso, tolera algumas variações. Podemos pensar na vagueza como a propriedade que alguns predicados possuem de admitir casos incertos ou limítrofes, os quais não permitem a clareza da extensão do predicado em si. Desse modo é difícil entender a aplicabilidade do significado do predicado vago, como no caso do Paradoxo de Sorites.

Cançado (2012) traz alguns testes para diferenciarmos ambiguidade e vagueza. Um deles é o teste de ambiguidade de Kempson (1980), o qual consiste em acrescentar a palavra também como uma sentença reduzida, de modo a se valer de uma ideia de identidade entre a primeira sentença e a inferência possibilitada pela reduzida. Se for possível mais de uma interpretação na principal, o mesmo deverá ocorrer na segunda, como no exemplo (13).

(13) Jorge lê na cama; Mara também.

Está claro em (13) que "Mara lê na cama", mas em (14) verificamos uma ambiguidade:

(14) Jorge está no banco; Mara também. 
A ambiguidade ocorre aqui por causa dos diferentes sentidos possíveis para a palavra "banco". Não importa se estamos falando de um banco relacionado ao objeto que nos permite sentar ou o local onde depositamos nossas economias. Em (14) Jorge e Mara estão no mesmo "banco", pois não há a possibilidade semântica de que o "também" se refira a um "banco" diferente do descrito na sentença principal.

No entanto, em frases como (15), que trazem termos vagos, Cançado (2012) aponta que não há como visualizar propriedades não especificadas do sentido pela identidade provida pela sentença reduzida por "também". Isso porque, segundo a autora, é possível que os dois sujeitos em (15) estejam realizando a ação em pessoas diferentes.

(15) Jorge abraçou Mara; o Pedro também.

Esses exemplos são baseados nos apresentados por Cançado (2012) para corroborar noções especificadas por Chierchia e McConnell-Ginet (1990) e nos mostram que a interpretação da propriedade das duas sentenças não vem diretamente do contexto, pois as expressões linguísticas não nos permitem especificar o sentido a ser adotado. Ou seja, é o contexto que acrescentará informações que não estão embutidas no sentido das sentenças para podermos delimitar o significado. Isso quer dizer que podemos tratar essa propriedade referente a "abraçar" como vaga e não como ambígua. Um teste semelhante a esse abordado por Cançado é proposto pelos autores Chierchia e McConnell-Ginet (1990), os quais destacam que uma paráfrase pode ressaltar a questão, caso a sentença original e a paráfrase possibilitem o mesmo acarretamento de ideias. Os autores afirmam que isso ocorre pelo menos no nível semântico, pois as ambiguidades e vaguezas no nível pragmático precisariam de um contexto dado ou construído.
Chierchia e McConnell-Ginet (1990) acreditam que o fenômeno da vagueza é um desafio para a semântica, mas que é recorrente e relevante na linguagem natural. Os autores tratam do predicado cadeira, no qual, em algumas situações, podemos afirmar que não há sombra de dúvidas que se trata de uma cadeira e, em outras, que temos certeza de não ser uma cadeira. Entre essas duas opções há um espaço de possibilidades em uma gradação que poderíamos pensar iniciando em "cadeira", passando por "banquinho" e terminando em "poltrona".

Para os autores (1990), a noção de vagueza como imprecisão semântica vem de que "a ideia básica é que sua contribuição para as condições de verdade é indeterminada porque o critério que temos não é suficientemente preciso" (CHIERCHIA; MCCONNELL-GINET, 1990, p.389). Uma das ilustrações que eles fornecem é sobre a gradação de cores. Quando, por exemplo, perguntamos para alguém qual a cor da sua camiseta preferida e a pessoa responde "vermelha", não temos como saber sobre qual vermelho está falando, como em (16), (17), (18) e (19).

(16) A cor preferida de camiseta é vermelha.

(17) A cor preferida de camiseta é laranja.

(18) A cor preferida de camiseta é meio vermelha.

(19) A cor preferida de camiseta é vermelho-alaranjada.

Poderia ser um tom de vermelho escuro, como o bordô, ou até mesmo uma camiseta laranja. Todas essas opções satisfazem a condição de verdade de ser vermelho, mas também podem não cumprir os requisitos. Isso porque há um contínuo entre as cores, ou tons, que podem ser considerados dentro do predicado "vermelha", de modo a não permitir um conjunto bem definido do limite do sentido, o que o coloca entre os predicados vagos. Em (16) podemos afirmar que a condição de verdade de ser "vermelha" é 
satisfeita, mas em (18) e (19) essa garantia é menor. Em (17) possivelmente a condição de verdade de ser "vermelha" é falsa.

Ao usarmos as cores como predicados, a vagueza é exposta por não termos certeza do referente, mas a noção do que seria um vermelho é, até certo ponto, fixa, em uma noção que Chierchia e McConnell-Ginet (1990) tratam como prototípica. No entanto, há uma outra forma de vagueza que pode ser expressa na língua, que está presente em predicados como os referentes à altura e espessura, como ilustramos em (20) e (21).

(20) Jerônimo é gordo.

(21) Gustavo é gordo.

Em (20) e (21), não há como fazermos uma gradação prototípica do predicado "gordo", mesmo que consideremos uma média do que pode ser considerado gordo. Segundo Chierchia e McConnell-Ginet (1990) e Cançado (2012), com predicados do tipo cores é possível haver uma concordância entre os comunicadores do que é considerado verde ou azul, pois não há como diferir muito no espectro das cores, mesmo dentre os muitos tons. $\mathrm{O}$ mesmo não ocorre nos exemplos (20) e (21), nos quais podemos ter uma noção do que é considerado gordo, por meio de convenções e cálculos de gordura corporal, mas mesmo essas normas não são consenso. Ou seja, no cotidiano, muitas vezes, uma pessoa é considerada gorda por A e por B não. Assim não há como considerarmos um protótipo para uma gradação do predicado "gordo".

Vamos presumir, como meio de ilustração, que Jerônimo e Gustavo, em (20) e (21), têm respectivamente $80 \mathrm{~kg}$ e $120 \mathrm{~kg}$. Os dois exemplos poderiam ser verdade, mas é difícil afirmarmos com certeza se os dois suprem totalmente as condições de verdade do predicado. Provavelmente em (21) é satisfeita a condição de verdade da sentença, mas o "gordo" em (20) pode não ser totalmente verdade, deixando incompleta a noção de verdade ou de falsidade da frase, ou pelo menos introduzindo uma espécie de meio termo para elas.

Ilari (2001) destaca que, quando nos referimos a um mesmo objeto, como nos exemplos (20) e (21), é bastante difícil formatar critérios para evitar a vagueza, mas não apenas quando se trata do mesmo objeto. Basta que seja o mesmo predicado com palavras vagas e objetos diferentes para ressaltar a vagueza e a dificuldade de localizá-la em uma escala. Assim como em (20) e (21), em (22) e (23) as sentenças ainda são consideradas vagas, mas é menos difícil ordená-las em uma escala de interpretação, mesmo que (20), (21), (22) e (23) satisfação a mesma condição de verdade para o predicado "gordo".

(22) O gato é gordo.

(23) O hipopótamo é gordo.

Chierchia e McConnell-Ginet (1990) concluem então que a questão desses predicados vagos, que causam certa difusão na área do significado, só pode ser resolvida através de contexto, ao contrário dos predicados como os de cor que, apesar de serem vagos, não são dependentes de contexto. No entanto, mesmo relativizando a interpretação com o contexto, isso não seria suficiente para resolver o problema da vagueza de sentenças como (20) e (21), conforme podemos observar nas palavras dos autores:

As condições de verdade para uma sentença são definidas em relação a contextos, cuja base comum envolve os pressupostos da sentença e, então, apenas para os índices incluídos na base comum. 0 tipo de parcialidade que precisaremos para lidar com a imprecisão, entretanto, será diferente ${ }^{3}$ (CHIERCHIA; MCCONNELL, 1990, p. 390, tradução nossa).

3 Do original: The truth conditions for a sentence were defined only relative to contexts whose common ground entailed the sentence's presuppositions and then only for indices included in that common ground. The kind of partiality we will need to deal with vagueness, however, is going to be different. 
O contexto serviria então, pelo menos, para podermos situar a interpretação em uma zona entre o que é verdadeiro e o que é falso, ou seja, o que se aproxima mais ao sentido pretendido ou o que se afasta mais. Esse tipo de problema não ocorre apenas com predicados de medição, como alto, magro, grosso, fino, mas em predicados cujos limites de significados são difíceis de delimitar, como ocorre nos exemplos (1), (2) e (3) com o predicado criança, que retomamos aqui.

(1) João é uma criança de 2 anos.

(2) O filho de Maria é uma criança de 13 anos.

(3) Paula é uma criança de 16 anos.

“Criança”, nesses exemplos, pode ser delimitada em uma gradação de "criança", "mais criança" ou "menos criança”, em uma ideia de verdade, mais verdade e menos verdade, colocando (1), (2) e (3) em um contínuo que seria o contexto. Esse contexto possibilita uma comparação, já que não há uma noção exata de quando uma criança perde a propriedade "criança". Em todo o caso, a vagueza do predicado não é resolvida, mantendo-se a incerteza, ou pelo menos a falta de definição exata, do limite fronteiriço da condição de verdade do predicado.

Apesar de acreditarem que a semântica necessitaria ser moldada para explicar esse fenômeno, os dois linguistas concordam com a possibilidade de o tratarem com modos formais. "Muitas imprecisões das características distintivas da imprecisão não surgem simplesmente de considerações de fatores contextuais e discursivos que levam a definições incompletas da verdade" (CHIERCHIA; MCCONNELL-GINET, 1990, p. 391). Ignorando essas propriedades, é possível projetar a vagueza de forma sistematizada. Os dois modos formais com que Chierchia e McConnell-Ginet lidam estão, de certo modo, apresentados nos casos listados como jeitos recorrentes de abordar o paradoxo de Sorites por Petrillo (2005), que apresentamos na seção anterior.

As duas formas de abordar a vagueza que Chierchia e McConnell-Ginet (1990) observam é a supervaloração e a lógica difusa. No entanto, os autores acreditam que a supervaloração é mais adequada para o estudo semântico da vagueza. Ela é uma lógica trivalente, que utiliza mais de dois valores de verdade distintos (ao contrário da lógica tradicional, que é bivalente). Essa formulação para o fenômeno da vagueza faz uso de uma supervalorização das condições de verdade da interpretação considerada padrão para criar uma escala intermediária de valores com as outras interpretações do predicado. Essa ideia nos remete ao caso (ii) destacado por Petrillo (2005), que abordamos na seção anterior.

ii. Contestar a verdade de uma das premissas genéricas ou de algum condicional.

No caso do proposto pelos semanticistas, a verdade do escopo do predicado seria questionada por possibilitar interpretações que não possam ser consideradas totalmente verdadeiras ou totalmente falsas. Como dissemos anteriormente, nessa situação, é possível aceitarmos uma "mais verdade" ou uma "menos verdade". Ou seja, a cada interpretação do predicado é dado um valor que se iguala a zero (quando falso) e 1 (quando verdadeiro), e isso define um certo limite do sentido da palavra. Depois, aos outros predicados são atribuídos valores entre 0 e 1, conforme a proximidade da verdade ou da falsidade, delimitando um montante mínimo e um máximo. Portanto, o que o filósofo, em cujo trabalho nos detivemos na seção anterior, observa como uma abordagem problemática para a vagueza (pelo menos no que concerne ao paradoxo de Sorites), os linguistas têm como uma saída para a questão da interpretação do predicado vago. 
Nos exemplos das cores das camisetas, que vimos nessa seção, poderíamos grosseiramente atribuir os valores a seguir:

(16) A cor preferida de camiseta é vermelha.

Valor: 1

(17) A cor preferida de camiseta é laranja.

Valor: 0

(18) A cor preferida de camiseta é meio vermelha.

Valor: 0.55

(19) A cor preferida de camiseta é vermelho-alaranjada.

Valor: 0.45

Isso se justifica porque (19) está mais próxima de (17) e (18) de (16); portanto, (18) é "mais verdade" do que (19).

Nessa segunda seção, procuramos apresentar de forma breve como a questão de predicados vagos é vista por uma semântica que trabalha com a verdade, em contato direto com a lógica. Na seção seguinte, faremos uma aproximação entre o paradoxo de Sorites, apresentada na parte 1, e essa ideia de vagueza semântica.

\section{Vagueza e linguagem no paradoxo de Sorites}

Como vimos na primeira seção deste trabalho, o paradoxo de Sorites é um caso bastante interessante de vagueza. Todos os exemplos que trouxemos até aqui são passíveis de se transformarem em um argumento sorítico. Porém, vamos nos valer do clássico exemplo de predicado vago "alto", o qual se assemelha bastante ao predicado "gordo" dos exemplos (22) e (23).

Apesar disso, com finalidade de ilustração, faremos uso dos testes propostos nas duas seções anteriores para primeiro demonstrar a vagueza do predicado. Depois mostraremos como o predicado opera no argumento sorítico e, assim como "grão de areia e careca", desencadeia em um paradoxo de Sorites. Vejamos então as sentenças (24), (25), (26) e (27).
(24) João tem 2 metros, ele é alto.

(25) Maria tem 1,80 metro, ela é alta.

(26) Matias tem 1,70 metro, ele é alto.

(27) Jéssica tem 1,50 metro, ela é alta.

Como Chierchia e McConnell-Ginet (1990) apontam, o predicado "alto" em (24), (25) e (26) é ambíguo porque as pessoas não têm alturas próximas. Além disso, apesar de (24) e (25) satisfazerem a condição de verdade de "alto", em (26) e (27) talvez um acréscimo de contexto facilitaria a dissolução da vagueza, como no caso de sermos informados que Matias e Jéssica venham de uma família de anões.

Para termos uma noção mais nítida da escalaridade da vagueza, já que estamos refletindo sobre uma perspectiva formal do significado, devemos atribuir valores em uma escala de verdade e falsidade.
(24) Valor: 1
(25) Valor: 0.55
(26) Valor: 0.45
(27) Valor: 0

Esses valores são atribuídos de acordo com a proximidade de um valor mínimo (próximo à falsidade) e um valor máximo (próximo à verdade). Portanto, como em (24) temos certeza de que o predicado realmente cumpre a condição de verdade e em (27) a de falsidade, tais valores são mais adequados para ficarem nos extremos da escala. Isso porque dificilmente alguém discutiria que uma pessoa com 2 metros de altura não é alta. De maneira oposta um indivíduo com 1,50 metro não estaria dentro do escopo delimitado por "alto". Os graus internos ficam com (25), mais próximo da verdade, e (26), mais próximo da falsidade. 
No entanto, é bom ressaltar que as quatro sentenças poderiam satisfazer a condição de verdade do predicado se considerássemos um contexto adicional, o qual estabelecesse um parâmetro comparativo, por exemplo. Até porque, por exemplo, uma "girafa alta" e uma "pessoa alta" trazem uma dimensão diferente para o predicado, apesar de sentido semelhante.

Quanto ao paradoxo de Sorites, podemos demonstrá-lo com o método indutivo.

(28) Se tem 2 metros, é alto.

(29) Se tem 1,50 metro, não é alto.

(30) Se tem n metros é alto, também o seria $(n-1)$ metros.

(31) Se tem $n$ metros é alto, também o seria $(n+1)$ metros.

Desse modo, chegamos à conclusão de que não importa quantos metros a pessoa tenha, poderá ser considerada alta. Na linguagem, as condições de verdade mostrarão a vagueza do argumento como vimos neste trabalho. Em um encadeamento por modus ponens se mostraria o mesmo e, utilizando a questão da escala de verdade, podemos chegar aos valores de (24), (25), (26) e (27).

Esta foi uma breve demonstração do tratamento dado à propriedade da vagueza em trabalhos distintos. A importância dessa propriedade, é interessante lembrar, se dá por a utilizarmos frequentemente na linguagem cotidiana sem geralmente nos causar dúvida ou estranheza. No entanto, ainda há muito o que estudar e pesquisar para aprofundar os estudos da incerteza na linguagem.

\section{Considerações finais}

Neste trabalho, procuramos realizar uma explicitação da interface entre a lógica e a linguística em predicados vagos, particularmente em argumentos passíveis do paradoxo de Sorites. Mostramos, primeiramente, o paradoxo em si e algumas noções de como ele é visto na lógica estudada na filosofia. Em seguida, apresentamos a noção de vagueza em estudos da semântica formal, para então unirmos as duas partes na terceira seção.

Como a semântica formal é uma perspectiva semântica que se vale de conceitos da lógica para seus estudos, é compreensível que as abordagens de desenvolvimento nas seções 1 e 2 sejam semelhantes. Inclusive, a perspectiva adotada por Petrillo (2005), envolvendo os condicionais universais e existenciais, pode ser uma boa abordagem para o seguimento dessa pesquisa em termos estritamente semânticos.

Além disso, sabemos que a vagueza ainda é um caso não resolvido na linguagem, mas os estudos formais têm possibilitado uma maior aproximação entre os conceitos da lógica e os conceitos da linguística para a compreensão desse fenômeno. De modo a ressaltar os limites tênues de predicados vagos em expressões linguísticas utilizadas no cotidiano. Esperamos ter ajudado a contribuir de alguma forma e a fomentar o interesse linguístico sobre o assunto.

\section{Referências}

BACH, Emmon. Informal Lectures on Formal Semantics. New York: State University of New York, 1989.

BEHLE, Nanashara. Paradoxos: inferências semânticas e implicaturas pragmáticas. 2014. Dissertação (Mestrado em Letras) - Programa de Pós-Graduação em Letras, Pontifícia Universidade Católica do Rio Grande do Sul, Porto Alegre, 2014.

BEHLE, Nanashara. Os fenômenos da contradição e dos paradoxos: uma avaliação de teorias e de estudos da Pragmática Inferencial. 2019. Tese (Doutorado em Letras) Programa de Pós-Graduação em Letras, Pontifícia Universidade Católica do Rio Grande do Sul, Porto Alegre, 2019. 
CANÇADO, Márcia. Manual de semântica. São Paulo: Contexto, 2012.

CHIERCHIA, Gennaro; MCCONNELL-GINET, Sally. Meaning and grammar: an introduction to Semantics. Cambridge: MIT Press, 1990.

DUMMETT, Michael. Wang's paradox. In: DUMMETT, Michael. Truth and other enigmas. Cambridge: Harvard University Press, 1978. p. 248-269.

GRICE, Paul Herbert. Lógica e conversação. In: DASCAL, M. (org.). Fundamentos metodológicos da lingüística. São Paulo: Global, 1982.

HYDE, Dominic; RAFFMAN, Diana. Sorites paradox. In: ZALTA, Edward N. (ed.). The Stanford encyclopedia of philosophy. Stanford: The Metaphysics Research Lab, 2018 Disponível em: https://plato.stanford.edu/archives/sum2018/entries/soritesparadox/. Acesso em: 18 jun. 2019.

ILARI, Rodolfo. Introdução à semântica: brincando com a gramática. São Paulo: Contexto, 2001.

KEMPSON, Ruth M. Teoria semântica. Rio de Janeiro: Zahar, 1980.

OLIN, Doris. Paradox. Montreal: McGill-Queen's University Press, 2003.

PETRILLO, Paulo Roberto. Raciocínio difuso via lógicas moduladas: uma solução ao paradoxo do Sorites. 2005. Dissertação (Mestrado em Filosofia) - Instituto de Filosofia e Ciências Humanas, Universidade Estadual de Campinas, Campinas, 2005. Disponível em: http://www.repositorio.unicamp.br/bitstream/REPOSIP/281574/1/Petrillo_ PauloRoberto_M.pdf. Acesso em: 18 jun. 2019.

RESCHER, Nicholas. Paradoxes: their roots, range and resolution. Chicago: Open Court, 2001.

SPERBER, Dan; WILSON, Deirdre. Relevance: communication and cognition. 2. ed. Cambridge: Blackwell, 1995. 